\title{
LOS MUNDOS POSIBLES \\ DE CALDERÓN DE LA BARCA Y ROBERT LEPAGE
}

\author{
Andrea Ávila \\ The University of Western Ontario \\ Department of Modern Languages and Literatures \\ University College, Rm 115 \\ London, ON Canada N6A3K7 \\ lavilabe@uwo.ca
}

[Anuario calderoniano (ISSN: 1888-8046), 5, 2012, pp. 51-69]

El gran teatro del mundo, de Calderón de la Barca, y Possible Worlds, película del canadiense Robert Lepage ${ }^{1}$, tienen en común mucho más que incluir la palabra «Mundo» en sus títulos. Ambos trabajos poseen una visión de lo que es la vida y del papel que juega el ser humano en el universo; de cómo lo percibe, de cómo lo trasciende y de cómo se relaciona con él a través de las facultades que le son propias.

Ambas hablan - de acuerdo a las circunstancias de la época y a las herramientas tecnológicas y conocimiento científico con los que cada uno cuenta- de que el ser humano es más que sólo cuerpo y más que sólo mente. Muestran que en la fusión de los elementos fisicos y

\footnotetext{
${ }^{1}$ Del año 2010.
} 
mentales es donde podemos encontrar la esencia humana. A quienes observamos en el teatro o en el cine el desarrollo de los personajes, nos recuerdan también que como espectadores (o lectores) estamos llevando a cabo una tarea de reconocimiento de nosotros mismos y de nuestros semejantes a través de las historias que nos narran. Hacemos uso, como lo apuntó Mark Turner hace algunos años, de nuestra «literary mind, [wich] is not a separate kind of mind. The literary mind is the fundamental mind $»^{2}$.

Estas formas de ver el mundo cristalizan en la forma barroca y neobarroca de representarlo. Durante una entrevista para el portal del Townsend Center for the Humanities de la Universidad de California, Anthony Cascardi preguntaba a Robert Lepage acerca de una nueva ópera que había dirigido. El director quebequense decía que consideraba la ópera un género neobarroco, formado por una compleja red de relaciones entre cada una de las artes y que posee la facultad de extender esa red hacia el público. Esta característica neobarroca del género lo llevaba a interesarse por ella y considerarla un laboratorio de estudio. Cascardi intentaba llevar a Lepage a clasificar la ópera como un espectáculo posmoderno. Pero Lepage insistía en su postura: es neobarroca.

Así como las óperas dirigidas por Lepage, Possible Worlds se inscribe en una estética llena de signos, relaciones complejas y, como argumentaré, se toca en muchos vértices con la dramaturgia barroca de Calderón, fundada en este caso en la alegoría y en la necesidad de desenmascarar la futilidad de las meras apariencias. La película abreva de la tradición a la que pertenece el escritor español y actualiza su discurso.

Traer esta estética del teatro al cine ${ }^{3}$ y aplicar técnicas teatrales para realizar una película, no sólo es posible sino de lo más lógico para Lepage, gracias a una de sus teorías favoritas acerca del nacimiento del

2 Citado por Jaén, 2006, p. 15.

${ }^{3}$ Antes de ser llevada al cine, Possible Worlds fue una obra de teatro escrita por John Mighton, matemático y dramaturgo, interesado en los procesos sicofisiológicos del ser humano y en la teoría matemática de los mundos posibles. En la cinta se aborda la historia de George, un hombre de negocios con gran habilidad para los números, que ha sido atacado por el doctor Kebler. Este le ha robado el cerebro y lo mantiene con vida artificial en un contenedor. El cerebro de George 'vive' una gama de posibilidades de su existencia anterior en las que su esposa Joyce aparece con distin- 
teatro: una noche en la prehistoria, cuando los miembros de un clan estaban sentados alrededor del fuego contando los sucesos del día, uno de ellos decidió ponerse de pie y hacer movimientos para ilustrar su historia. Al darse cuenta de que el fuego provocaba que su propia sombra fuera más grande que él, la incorporó a su relato. El teatro se generó, entonces, con el uso de estas tecnologías primarias: el fuego y el ser humano en movimiento (UCBerkley).

Para Lepage, el cine nace al mismo tiempo, con la proyección de una imagen por la acción de la luz y la representación de la historia por parte de un individuo que se mueve. Los lenguajes que utilizan, transformados por tecnologías más avanzadas, se han diversificado, y la ortodoxia de los artistas ha separado lo que se originó junto.

Siempre con esta idea en mente, Lepage introduce el uso de tecnología digital en sus puestas en escena (tecno en scéne) para crear efectos visuales y sonoros que realcen sus tramas. Al mismo tiempo, utiliza tecnologías ancestrales como las sombras chinescas, para dar mayor emotividad y cuerpo a sus películas. Si Calderón fuera un artista en nuestro siglo, seguramente integraría también todas las herramientas que le ofrecería la era digital.

\section{LOS INTERSTICIOS, ESPACIOS ENTRE OTROS ESPACIOS}

En la teatralidad y el cine de Robert Lepage podemos encontrar una serie de espacios ambiguos que se pueden clasificar como in between: lugares habitados por los personajes que él presenta y, al mismo tiempo, imposibles de habitar de forma 'real', permanente. Aeropuertos, estacionamientos, cuartos de hotel, sitios de paso, hechos para estar en ellos un periodo corto y después dirigirse al destino principal. En el film Possible Worlds el director lleva la idea del espacio intersticial hasta el extremo, al mostrar el cuerpo del personaje central, George, privado de la vida pero con el cerebro preservado y estimulado a través de complicadas conexiones eléctricas y químicas. ¿Está vivo o no? Cuando una persona vive, pero su cerebro deja de funcionar, se le declara muerte cerebral. Cuando el cerebro de un individuo vive, pero el cuerpo está muerto, ¿se le puede seguir considerando vivo?

tas personalidades. El público sabe, desde el inicio de la obra y de la cinta, que George ha sido privado del cerebro. 
Ese espacio concebido entre la vida y la muerte, habitado por los pensamientos de George (alimentados por su propio asesino, el doctor Kebler, con estímulos físicos, químicos y de manera fundamental, con la conversación) es la imagen del espacio intersticial llevada más allá del límite.

En la obra El gran teatro del mundo este espacio in between se extiende a la vida entera del ser humano. Localizado entre la cuna y la tumba, Pedro Calderón de la Barca también ha llevado al extremo el espacio intersticial de la realidad humana. Al igual que el personaje de Lepage, atrapado en un hueco entre la vida y las representaciones mentales (imaginación, memoria), los personajes de Calderón están de paso en la vida, en un viaje preestablecido por Autor, el creador de la comedia que representan. A todos les ha sido asignado un papel momentáneo, temporal, para actuar (en el más extenso sentido de la palabra) en un espacio delimitado también por Autor: el Mundo.

Ninguna anécdota, gloria o penuria que los caracteres de El gran teatro del mundo puedan tener es más relevante o irrelevante que los recuerdos que el cerebro de George va reelaborando en diversas circunstancias, con el "guión» preparado por la manipulación del doctor Kebler. Para George, Kebler adquiere la misma categoría que el Autor en la obra de Calderón.

El grupo con el que Calderón representa a la humanidad (el Pobre, el Rico, el Rey, el Labrador, el Niño, y las alegorías de la Hermosura y la Discreción) no tiene la opción de elegir su papel, tampoco puede quejarse de lo que le ha tocado representar por la voluntad del Autor (a lo más, dice el Labrador, se quejará de su propia forma de interpretarlo; vv. 317-318). En este sentido, en apariencia, Lepage se despega de la propuesta de aquél dramaturgo al hablar de diferentes formas de existencia para un ser humano en una misma vida; sin embargo, no puede separarse tanto, ya que George, a quien se le ha dado la posibilidad de conocer esas vidas alternas entre las que transcurre su existencia, tampoco tiene la capacidad de elegirlas o controlarlas.

Por un lado, el personaje explica a Joyce, su esposa, la teoría de los mundos posibles ("each of us exists in innumerable ways» ${ }^{4}$ ) y por otro, admite que estas existencias pueden estar controladas desde fuera («Maybe someone is making us thinking what they want»). Las posi-

\footnotetext{
${ }^{4}$ Las citas de la película fueron extraídas de su versión en video.
} 
bilidades, entonces, se limitan al tipo de personaje que toca representar en un momento específico (como cuando George, tranquilo, asume que en ese mundo le toca ser un criminal atrapado por la policía), pero este personaje le sigue siendo asignado por un Autor (Kebler) que, en la visión de Lepage, controla lo que pensamos.

Esto se contrapone con la propuesta de Calderón de que a cada personaje se le dará «libre albedrío». En algún momento cada uno de ellos pregunta: "¿Qué he de hacer?», a lo que la Ley, en su papel de Apuntador, contestará: «Obrar bien, que Dios es Dios» ${ }^{5}$. Pero tendrán la posibilidad de ignorar el consejo, aunque el "pago» que les dé el Autor al final, consistente en una cena a su lado (la Eucaristía católica) dependerá de lo que elijan. El mismo Autor observa los momentos en que sus personajes van a tomar alguna decisión incorrecta, pero se reconoce impotente de cambiarla:

$$
\begin{aligned}
& \text { Yo bien pudiera enmendar } \\
& \text { los yerros que viendo estoy; } \\
& \text { pero por eso les di } \\
& \text { albedrío superior } \\
& \text { a las pasiones humanas, } \\
& \text { por no quitarles la acción } \\
& \text { de merecer con sus obras; } \\
& \text { y así dejo a todos hoy } \\
& \text { hacer libres sus papeles, } \\
& \text { y en aquella confusión } \\
& \text { donde obran todos juntos, } \\
& \text { miro en cada uno yo... } \\
& \text { (vv. 929-940) }
\end{aligned}
$$

Lepage por su parte, seducido por la idea de que un ser humano pueda vivir múltiples realidades, no puede dejar de lado que en una

${ }^{5}$ En los versos 805 al 807 el Pobre y el Rico preguntan qué deben hacer para vivir su situación particular. La Ley canta: «Obrar bien que Dios es Dios». El Mundo refuerza la idea metateatral de que hay un apuntador dictándoles las líneas correctas en los versos 833-834: «A cada uno va diciendo / el apunto lo mejor». Algunos, como el Labrador, no escucharán la instrucción (vv. 790-792), aunque el Autor ha dicho claramente "con el apunto a mi ley; / ella a todos os dirá / lo que habéis de hacer...» (vv. 479-480). 
de ellas «alguien» esté determinando sus pensamientos, por ende sus decisiones y las consecuencias que derivan de éstas.

Mientras, Calderón — quien no se alejaba de la idea canónica de que el gran Autor de la vida humana, el Dios de los católicos, había determinado ya el tipo de papel que le tocaría representar a cada actor- destaca la capacidad de ese intérprete de decidir cómo ha de dar vida al personaje, lo cual lo pone en la posibilidad de vivir la realidad como quiere que se produzca.

Para el español, la vida humana también puede repartirse en varias realidades y lo manifiesta cuando el Mundo dice a los actores: «Al teatro pasad de las verdades / que este el teatro es de las ficciones» (vv. 1387-1388). El teatro de las verdades y el teatro de las ficciones son realidades perfectamente separadas e identificables a simple vista, pero existen en un mismo universo y los actores viven cada una como una realidad total. Cada una tiene características de la otra y no sólo pueden confundirse, sino que se experimentan con igual intensidad; tienen periodos establecidos de duración, pero mientras se está en ellas (en la vida o en el escenario) los conflictos y alegrías que suceden son reales y hay que recibirlos de esa manera, como situaciones verdaderas y verosímiles.

Las visiones de Lepage y Calderón en sendas obras podrían parecer, a golpe de vista, antagónicas: las infinitas posibilidades del primero contra la trama preestablecida del segundo. Sin embargo, ni Lepage está tan seguro de que en esa multitud de opciones el personaje controle sus propios pensamientos, ni Calderón está tan convencido de que el Autor pueda garantizar cómo se portarán sus personajes. Ambos se mueven en la ambigüedad de desconocer el destino y el propósito de la vida humana, aunque Calderón crea en la existencia de una vida después de la muerte "sentado a la mesa del Autor» y Lepage se decante por una vida mental que podría trascender la del cuerpo.

Por lo mismo, ni los personajes de Calderón ni las situaciones que se plantean pueden tener una sola dirección o significado. Los elementos del decorado teatral no son sólo piezas de ornamento, sino parte de la vida misma, así como la vida está impregnada de fantasía y misterio. Para aclarar esta idea nos ayuda lo que Ferrater Mora dice: los Mundos de Calderón son

neither real nor ideal. It is a magic world: a world of wonders, symbols, and reflections. All this, of course, is typical of what happens on a stage, 
under the limelight. Calderon's world is fully, and almost exasperatingly, theatrical ${ }^{6}$.

De esta misma forma el mundo de Lepage está construido por símbolos y reflejos, como lo muestra la multitud de escenas en las que el agua, el espejo, una mesa pulida o las ventanas por las que escurre la lluvia nos devuelven lo que sucede, pero también lo ocultan; son pasajes a otro mundo, impiden la visibilidad o nos sugieren aspectos oscuros de la realidad.

En sus espectáculos teatrales y películas Lepage representa esos procesos de develar-ocultar con la utilización de alter egos. En Possible Worlds, el alter ego se convierte en las infinitas posibilidades de una vida humana, que pueden o no realizarse en ésta $u$ otras dimensiones. Los espejos han sido utilizados por Lepage en muchos de sus espectáculos para ilustrar la existencia de los alter ego. En Possible Worlds, donde se trata de varias «otras realidades», los espejos y el agua actúan como puerta de entrada a esos mundos posibles.

El cine lepagiano es también completamente teatral, se niega al uso cotidiano de la cámara para retratar «objetivamente» lo que tiene delante y la maneja para esconder y sorprender, como harían las máquinas de tramoya o las luces en el escenario: ninguna de las escenas de Possible Worlds nos da una pista sobre el lugar o la época en la que se lleva a cabo la acción. Lo más común (a lo que recurren las grandes producciones hollywoodenses, por ejemplo) sería abrir la narración con una toma de los edificios icónicos de las ciudades de Quebec o Montreal, en el caso de que el director quisiera establecer la trama en su provincia de origen. $\mathrm{O}$ que mostrara las placas de los autos como referencia al lugar; podría utilizar también los símbolos de los coches de policía para ubicar la acción. Lepage no sólo no los enfatiza, sino que los evita a propósito y nos sumerge en un ambiente sin localización concreta.

En cuanto al tiempo, contrariamente a lo que se hace en las producciones «mainstream», donde la identificación de la temporalidad es básica, la decoración de los escenarios y el vestuario de los personajes de Possible Worlds están diseñados para disfrazar la época. La iluminación es cambiante y misteriosa (como la describe Arseli Dokumasi):

${ }^{6}$ Ferrater Mora, 1984, p. 16. 
blue spot is swept by white... A white one by blue... Although not distinct to my naked eye, it's very probable that a red spot is wiped off by green, or pink by yellow, or brown by orange, or... Neither evening nor morning, either dusk or dawn but it's impossible to tell apart... I can almost feel the weather... Splashes of water regress, splashes of water progress ... Moments of indecision define their path. Shifting tones of blues let the tides wave along while a meditative melody repeats same two notes over and over ... I could neither speak of figure nor ground, yet I cannot either keep myself from feeling the two in an indistinct way. It is as if I am within both at the same moment, if there is any moment as such... ${ }^{7}$

La luz nos impide fijar un punto en el tiempo. La realidad del personaje principal, George, puede ser cualquiera, en el presente, pasado o futuro, en la mañana o en la tarde, en Quebec o en México. Estos elementos, a diferencia de la forma en que lo hacen las películas de alto presupuesto, son usados para tratar de transmitir sensaciones y emociones al espectador a la manera en que lo hacen los espectáculos en vivo, según lo afirma el propio Lepage ${ }^{8}$.

Para el director quebequense, provocar emoción es lo fundamental tanto en el cine como en el teatro. Dokumasi, investigadora canadiense de medios audiovisuales, subraya que la iluminación de Possible Worlds es profundamente evocadora de variables como la hora del día, el clima; pero también de reacciones emotivas, como la indecisión o la desorientación que implica no poderse ubicar en la fecha o el lugar determinado.

El teatro de Calderón es efectivo al provocar emoción, aunque no por la confusión, como Lepage, sino por la profunda identificación que produce en sus espectadores. En el caso que nos ocupa, la obra abre con la introducción de personajes y tipos alegóricos que representarán a toda la humanidad. Al no escenificar personajes con historias individuales, cada sector del público se ubica en una categoría y se identifica fuertemente con el comportamiento de los personajes en escena y, particularmente, con los posibles premios o castigos que éstos reciban según su comportamiento y decisiones.

7 Dokumasi, 2008, pp. 11-12.

${ }^{8}$ En Dundjerovic, 2003, p. 131. 
La travesía por el escenario, de la cuna a la tumba, es un elemento que engloba a todos los seres humanos y emotivamente ejecuta un vínculo entre personajes y audiencia; lo mismo ocurre con la parte preceptiva, en la que la sencilla norma «obrar bien, que Dios es Dios» se aplica por igual como regla de vida a toda persona creyente. Como menciona Brian Boyd: "Art as a cognitive play augments our capacities so that we can... efficiently produce ideas and actions... in the case of story, scenarios of reasoning about our own and others' plans and actions» ${ }^{9}$. Al contemplar una obra de arte, nuestra capacidad para razonar sobre planes y acciones propios y de los demás se beneficia.

El público de El gran teatro del mundo podrá inferir, gracias a esa capacidad cognitiva, qué comportamiento le es más conveniente y aplicarlo en su propia vida a través del conocimiento que le brinda la historia representada, sin necesidad de experimentarlo en carne propia. Esto también le producirá un impacto emotivo al reconocer las consecuencias que podría enfrentar si actúa en una forma u otra.

Isabel Jaén Portillo subraya que «los elementos emocionales [son] componente esencial de la cognición humana» ${ }^{10}$ y se entremezclan con las experiencias vitales que el lector (para Jaén Portillo) y el espectador de una pieza teatral o cinematográfica (para nosotros) aportan cuando se enfrentan a un texto o puesta en escena y deben otorgarle un significado. Al momento de enfrentarse a personajes que realizan acciones similares, la capacidad cognitiva extraerá la experiencia que estos aportan y la matizará con la paleta de la emoción que, por dicha experiencia, corresponde al hecho.

Volviendo a Possible Worlds, hablamos de mundos que no son «Otros», sino simplemente variaciones de la realidad que George conoce, a pesar de que en uno de ellos su amada Joyce sea quien lo aborde en la barra de un bar, o que en otro le cueste varios encuentros arrancarle una cita; esto no altera la realidad de que ella es su amor. Como lo dice la propia Joyce, al hablar de la existencia de mundos paralelos:

cuando le plantean a la gente la posibilidad de imaginar una vida diferente, siempre piensan en trivialidades. ¿Qué hubiera pasado si me hu-

${ }^{9}$ Boyd, 2009, p. 95.

${ }^{10}$ Jaén Portillo, 2006, p. 20. 
biera casado con esta persona y no con aquélla? Nunca piensan, por ejemplo, ¿qué pasaría si tuviera dos cerebros?

En el caso de George, cuyo cerebro flota en un líquido (como todos los que forman los portales a los mundos posibles), su capacidad de imaginar aparece limitada a su pasado inmediato, a lo que conoce, al recuerdo. No puede imaginar nada distinto a lo que ya le ha sucedido porque ahora carece de cuerpo; dentro de sus posibilidades no existe ya la de percibir la realidad a través de los sentidos. No tiene una imaginación que lo proyecte al futuro, sólo rememora.

El cerebro de George está condenado a vivir en tiempo pasado, reproduciendo una emoción — el amor que siente por su esposa- y reflejándola en cualquier escenario posible en el que ambos pudieran haberse conocido. La que cambia es ella: en cada mundo posible no sólo viste y se arregla de forma diferente. También actúa y piensa distinto gracias a que George, en la circunstancia de la película, no necesita experimentar sensaciones para imaginarla a ella diferente.

George, que no cambia, la ama en cada posibilidad; no puede transformar su emoción o dejar de amar porque ha sido separado de su cuerpo, el que le proveía de experiencias para que su capacidad cognitiva imaginara opciones para sí mismo (además de la carencia evidente de la posibilidad de llevarlas a la práctica pues ya no tiene cuerpo). Ha quedado reducido a una «media consciencia» ya que «nuestras actividades mentales... están directamente relacionadas con nuestra experiencia corporal en interacción con lo que nos rodea» ${ }^{11}$. Sus mundos posibles tendrán que irse volviendo cada vez más escasos conforme opere la otra capacidad de la mente: el olvido.

\section{MetateAtro, metacine, METARREALIDAD}

En la teatralidad calderoniana que Ferrater Mora llega a considerar casi exasperante, sobresale el uso del metateatro que ya en 1964 Lionel Abel llegó a proclamar «un nuevo género» dentro de la escena. Todo en El gran teatro del mundo es metateatral, desde el título hasta los personajes, pasando por la analogía que el dramaturgo traza en-

11 Jaén Portillo, 2006, p. 15. 
tre la vida humana y el paso por el escenario como un trayecto desde la cuna hasta la tumba.

Volvamos a considerar el elemento de que Calderón hace transitar a sus personajes de un extremo a otro del escenario, que representa la vida, y les facilita un apuntador (lo hace el Autor, de hecho) para cuando olviden la acción recomendada para llevar a buen término la función: Obrar bien, que Dios es Dios. La función de este apuntador, elemento del teatro, la tiene la Ley, herramienta de Dios para guiar a quienes creen en él. Con esto el dramaturgo asegura a su público que ellos, como personajes que son en la trama «real», también tienen un elemento que les auxilia a guiarse cuando olvidan el "guión» de lo que debe hacerse para llevar una buena vida, y esa es la Ley de Dios. De esta forma extiende la anécdota del escenario a la realidad de forma directa.

Para remarcar la fusión de teatro y experiencia, Calderón envía a sus caracteres con el Mundo, para que sea éste, en su calidad de director de los actores, el que les brinde las prendas y características que los distinguirán según su personaje: la ropa, las joyas, la carencia de éstas, las herramientas de trabajo, los atributos en general con los cuales cada uno se distingue. Estos les son asignados a la vista del público, reforzando la identificación y resaltando que toda la gente llega al mundo con ciertas características que les darán personalidad. Basado en esta técnica primaria, construirá el universo de la obra.

Lepage en Possible Worlds hace "metacine», no a través de las palabras o de la trama, sino de las imágenes, la parte fundamental del lenguaje cinematográfico. La escena de apertura de la historia se lleva a cabo en el departamento de George, quien yace tendido en el suelo y es descubierto por un trabajador que limpia el ventanal. Los cristales ya sea bañados por la lluvia o en la penumbra, se convierten en una pantalla sobre la cual son proyectadas las escenas que vemos en esa locación. Lo mismo ocurre con la ventana del comedor en el que George se encuentra en un par de ocasiones con su esposa, Joyce.

Estas superficies enmarcan la acción, la delimitan, de la misma manera en que la pantalla del cine nos encuadra qué parte de lo que tenemos delante de nosotros es la película y cuál es el resto del espacio en medio de la oscuridad. Dónde están los personajes y dónde la gente con quien compartimos la experiencia de observar la historia. Al ver Possible Worlds en el cine (y, en menor medida, en una televisión 
o computadora) nos enfrentamos a una pantalla que proyecta otra pantalla sobre la cual, a su vez, se proyectan las imágenes que nos interesan. Esto también nos remite, automáticamente, al uso del ciclorama en teatro.

Otra forma en que Lepage hace una retórica del cine dentro del cine son las disolvencias de una realidad hacia otra que se realizan a través de los espejos de agua o "portales» a los mundos posibles. En estas escenas, como lo resalta Aleksandar Dundjerovic, Lepage está «citando» con imágenes a Jean Cocteau, a quien el director quebequense considera una de sus grandes influencias cinematográficas:

In Jean Cocteau's Orpheus... he always says "Well, we're here in this room and now if we want to go into the world of death, or something, we have to go through the mirror». But he can't go to the mirror the same way; every time he has to find a different way ${ }^{12}$.

Lepage también elude ir de una realidad a otra de la misma manera, así que aún utilizando el agua, lo hace siempre diferente: a través del ventanal; del tanque de flotación en el que se relaja el científico asesino; de una mesa pulida que parece un espejo de agua; a través del vaso con agua o de la sopa, siempre en referencia a un signo cinematográfico reconocible, citable, de la obra de Cocteau. Eso sucede de manera análoga a los personajes de Calderón haciendo referencia a una herramienta teatral, como el vestuario o la escenografia citando al teatro.

El agua se convierte en el espejo que no sólo refleja, sino es reflejada. Ferrater Mora nos dice que para Calderón, la realidad se parece a un espejo infinito (mise en abysme), en el que las realidades del mundo (el teatro) reflejan las realidades espirituales (Dios y su creación) y viceversa, de forma interminable. Si el Autor es Dios, el dramaturgo es una especie de dios para sus personajes; el dramaturgodios devuelve el reflejo del escritor cuando no puede determinar el comportamiento de sus personajes; el dramaturgo refleja al dios al brindarles un apuntador a los actores y así al infinito, cuando cada realidad refleja a la otra en sus características, funciones y detalles. Según Ferrater, para Calderón no hay distingo entre el espejo y el reflejo ${ }^{13}$.

12 Dundjerovic, 2003, p. 25.

13 Ferrater Mora, 1984, p. 4. 


\section{TECNO EN SCÉNE}

La espectacularidad de la puesta en escena de las obras de Calderón dependía, sin lugar a dudas, del lugar donde fueran representadas y el público al que iban dirigidas. Para las comedias que había que representar en Palacio, el dramaturgo hacía un despliegue de recursos tecnológicos, como trampas, poleas, deus ex machina y todo lo que la ingeniería teatral de su tiempo pudiera brindarle. F. R. de la Flor nos dice que Calderón es el «dramaturgo del exceso» y que hace un «teatro de masas» ${ }^{14}$.

Aunque los autos sacramentales no corresponden a la descripción de excesivos, ya que su localización en los carros de Corpus limitaban el despliegue de artificios comparados con las obras palaciegas, Josefa Badía nos señala que para este auto en particular Calderón establece el uso de tres carros y de una gran esfera en un nivel superior en la que estaría el Autor, además de otra de menor tamaño de la que saldría el Mundo. Ambas deben haber estado concebidas para que la presentación de estos dos personajes tuviera un efecto de sorpresa y maravilla para los espectadores.

Según Badía El gran teatro del mundo se encuentra entre dos periodos de la producción de Calderón: el de las obras que recurrían a elementos tecnológicos «moderados» y las de gran despliegue. El gran teatro del mundo debería corresponder a la etapa de «menor aparato escénico, y la de obras más directas, emotivas y de mayor fuerza dramática» ${ }^{15}$, en la que el autor experimentaba con una mayor espectacularidad, lo que perfilaba la identidad de su teatro.

Calderón estaba al tanto de que la espectacularidad, la sorpresa y el engrandecimiento de las figuras escénicas provocaban el acercamiento emotivo del público al asunto que se representaba. Pero, al igual que Lepage, sabía que las historias son la base para que cualquier despliegue escénico surta efecto. En palabras del quebequense, la tecnología utilizada tanto en una producción teatral como en una cinematográfica, debe basarse en una narrativa que involucre asuntos «larger than life», historias impactantes, no cotidianas, que permitan su representación en escala espectacular.

${ }^{14}$ De la Flor, 2002, p. 10.

15 Badía Herrera, 2003, p. 5. 
En El gran teatro del mundo, acudimos a la escenificación del trayecto y destino de la vida humana, desde la cuna hasta la tumba, destino común a todas las personas. Es, sin duda, una historia mucho más grande que la vida. En Possible Worlds, el planteamiento de la infinidad de posibilidades para ser humano en una misma existencia rebasa con mucho el horizonte de las experiencias personales y plantea conflictos que superan la individualidad. La característica de presentar asuntos que trasciendan el ámbito de una vida humana no es exclusiva de la estética barroca o neobarroca, pero en éstas se presentan de una forma espectacular, amplia en el alcance de un público, a diferencia de la estética moderna que hace énfasis en llegar al individuo, con perspectivas intimistas, unipersonales y sicologistas. Calderón y Lepage, en este sentido, se alejan de la perspectiva individual para acceder a narrativas que son «larger than life», más allá de la vida de una sola persona.

Basado en estas historias fundamentales - que a veces pueden tener una anécdota muy simple, pero que impactan a muchos públicos porque son universales - Lepage utiliza también todas las tecnologías que están a su alcance: en esta época, las herramientas digitales son fundamentales y él las integra en sus espectáculos teatrales y, a su vez, lleva al cine los elementos del teatro. En Possible Worlds, además del ya citado uso de las pantallas o cicloramas, Lepage recurre a los juegos de sombras para realzar la presencia de sus personajes. Cuando George y Joyce almuerzan en el comedor del laboratorio, la cámara se aleja y el espectador pierde los detalles de la fisonomía de ambos y del resto de las personas que los rodean. Esto brinda una atmósfera onírica a toda la escena que conviene a la situación de George como habitante de un espacio in between.

Al igual que Calderón considera al actor y la voz de éste uno de los elementos tecnológicos del teatro ${ }^{16}$, Lepage busca utilizar todos los registros y tonalidades tanto del gesto como de la palabra en sus actores. Sin embargo, a mi parecer, Lepage no llega al extremo que clama Christopher Innes: «In this post-industrial, post-national, post-human formula Lepage has become the poster-artist for an aggressive postmodernism» ${ }^{17}$. Innes afirma que Lepage se inscribe en la línea de

${ }^{16}$ Ver Badía Herrera, 2003, p. 29.

${ }^{17}$ Innes, 2005, p. 125. 
Gordon Craig, quien consideraba al actor una "supermarioneta» completamente adecuada a los deseos del director - mente superior-, quien le daba sentido a sus movimientos.

En mi opinión, considerar a Lepage dentro de la tradición de la modernidad, que veía a los actores como máquinas inevitables pero indeseables, vacías de sentido y pensamiento y al público como receptor acrítico de los resultados de su arte, es conocer poco del concepto de teatro y cine de Lepage así como de su forma de trabajo.

En La Casserne, el taller-laboratorio-teatro de la compañía Ex Machina, fundada por Lepage, los actores experimentan y proponen líneas de acción para las obras. El grupo se apoya en la improvisación como técnica para formar las puestas en escena, más a la manera de partituras musicales que de guiones teatrales, ejercicio en el que el dramaturgo y el director se dedican a detectar los mejores momentos que surgen de estos ensayos para incorporarlos a la trama de la obra.

Más que parecerse a los procesos del director o dramaturgo como pieza central del drama, a la manera de Peter Brook, Robert Wilson o el ya citado Gordon Craig, Lepage mira más atrás, al tiempo en el que una compañía contaba con un texto base pero era libre de interpretarlo sin la figura casi dictatorial del director como la conocimos en la modernidad, o del autor que no permite que se cambie una palabra en sus parlamentos.

Este es otro punto más en el que Lepage, aún con el uso de los ensayos en línea, los efectos digitales y toda la parafernalia tecnológica de que dispone, se acerca más al espectáculo del siglo Xvir que al teatro individualista, centrado en el director, que conocimos en el siglo xx. Otro argumento de por qué, en lugar de aproximarse a la posmodernidad, como lo quiere Anthony Cascardi, Lepage se coloca más cerca de Calderón. Porque se dirige un público que él entiende básicamente como humano; porque trata a los actores como parte de la misma especie. Es también uno de los motivos por los que Lepage se asume neobarroco.

A MANERA DE CONCLUSIÓN: MISE EN SCENE, MISE EN ABYME, TECNO EN SCENE

Si el teatro y el cine tienen un mismo origen y lenguajes diferenciados apenas por la especialización, como quiere pensar Lepage, po- 
demos observar que hay puentes muy transitados entre ellos. Son muchos los realizadores de cine que han llegado a la pantalla grande por el camino de la representación teatral, aprendiendo desde el lenguaje básico en las tablas. Sergei Einsestein dejó el teatro, seducido por las posibilidades creativas que le ofrecía el cine como nuevo medio tecnológico, en particular la herramienta del montaje que le permitía transitar entre realidades sin necesidad de explicarse con palabras. Dundjerovic $^{18}$ cita a Orson Welles y Jean Cocteau como directores y dramaturgos que entendieron que los códigos del escenario y la pantalla están íntimamente ligados.

Lepage, quien tiene como primera formación la de actor, aprecia dos cosas fundamentales: la delgada línea que divide ambos lenguajes y la necesidad de historias universales que hagan sentir al espectador - no al actor, en su concepto, que contrasta con el de las técnicas modernas de actuación - la emociones contenidas en los dramas que se representan.

De esto sabía mucho Calderón, quien trabajaba sus historias pensando en conmover a la audiencia, llegar hasta su más profunda emotividad e incluso, a modificar su comportamiento. Para lograr la emoción del público ambos creadores echan mano del reflejo de realidades superiores en escenas cotidianas. Y viceversa, el reflejo de lo cotidiano en las historias maravillosas que nos hablan de la divinidad y de la ciencia; de la trascendencia y el amor de pareja; de los avances tecnológicos y el valor de percibir la realidad con nuestros propios sentidos. Esta puesta en abismo, este "estadio del espejo", haciendo referencia a la teoría de Jaques Lacan, nos enfrenta con lo que somos y lo que podemos ser en una eterna relación de nosotros mismos como otros a los que podemos percibir pero nunca aprehender por completo.

Los trabajos de Calderón y Lepage coinciden en una puesta en escena rica en recursos técnicos, basada en la perspectiva especular que proyecta infinitas posibilidades de una sola realidad, la vida humana, llena de potencial para ir de la individualidad a una dimensión universal y con la perspectiva de trascender su propio momento de existencia. La puesta en abismo que resulta del uso de los reflejos en cada una de las piezas no sólo favorece la identificación del público con

${ }^{18}$ Dundjerovic, 2003, p. 11. 
los personajes que ve en el escenario o en la pantalla, sino que magnifica la propia situación humana del espectador que continuará proyectando su imagen en ese espejo.

Convertida en reflejo, reproducirá su historia, desde el pasado y hacia el futuro, aunque también en retrospectiva, o de manera fragmentada tomando solamente algunos de los muchos pedazos de su realidad. Propiciará un intercambio interminable de escenas suyas de la vida real, pero también de historias imaginadas, porque en cada persona se encierra el germen de todos los mundos posibles. 


\section{Bibliografía}

Abel, L., Metatheatre. A New View of Dramatic Form, New York, Hill and Wang, 1964.

Boyd, B., On the Origin of Stories, London, The Belknap Press of Harvard University, 2009.

Badía Herrera, J., «Indagación sobre las posibilidades dramáticas del Gran Teatro del Mundo", Ars Theatrica: Estudios e Investigación, 2003. Disponible en: <http://parnaseo.uv.es/Ars/Estudios/J_Badia.htm>.

Calderón de la Barca, P., El gran teatro del mundo, ed. D.Ynduráin, Madrid, Alhambra, 1981.

De la Flor, J. R., «Prólogo: Theatrum Mundi» en V. Martín, V., El concepto de representación en los Autos Sacramentales de Calderón, Kassel, Reichenberger, 2002, pp. 9-16.

Dokumaci, A., «Filmic Experience and Critical Writing on Film as Performance», Paper presented at the annual meeting of the International Communication Association. Montreal, Quebec, Canada.

Ver <http://www.allacademic.com/meta/p232808_index.html>, 2008, non available>.

Dundjerovic, A. S., The cinema of Robert Lepage. The poetics of memory, London, Wallflower, 2003.

- The Theatricality of Robert Lepage, Montreal / Kingston, McGill / Queen's University Press, 2007.

Ferrater Mora, J., «The World of Calderón», Hispanic Review, 52.1, 1984, pp. 1-17.

Fiore, R. L., "Calderón's El gran teatro del mundo: An Ethical Interpretation», Hispanic Review, 40.1, 1972, pp. 40-52.

InNES, C., "Puppets and Machines of the Mind: Robert Lepage and the Modernist Heritage», Theatre Research International, 30, 2005, pp. 124-138.

JaÉn Portillo, I., Estados de consciencia: Psicología congnitiva y literatura en la España del Siglo de Oro, West Lafayette, Purdue University, 2006. [Tesis doctoral inédita.]

Lipman, S., "“Metatheater" and the Criticism of the Comedia», Modern Language Notes, 91.2, 1976, pp. 231-246.

Possible Worlds, dir. R. Lepage, int. T. McCamus y T. Swinton, 2000.

Parker, A. A., Los autos sacramentales de Calderón, Barcelona, Ariel, 1983. [Original en Oxford, Dolphin Book, 1943.]

Pedraza Jiménez, F. B. «Notas sobre la técnica dramática calderoniana», en Calderón desde el 2000 (Simposio Internacional Complutense), ed. J. M. ${ }^{a}$ Díez Borque, Madrid, Ollero \& Ramos, 2001, pp. 293-319.

UCBerkley. YouTube, 14 de noviembre de 2007, 2 de octubre de 2009. Ver: $<$ http: / $/$ www.youtube.com $/$ watch? $=$ sqhUSm451gI\&feature $=$ related $>$. 
Wardropper, B. W., «The unconscious Mind in Calderon's El pintor de su deshonra», Hispanic Review, 18.4, 1950, pp. 285-301. 